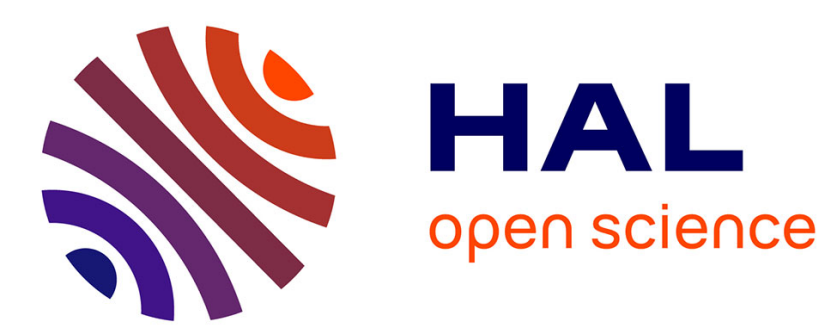

\title{
Mechanical behaviour of Fe-C alloys during phase transformations
}

E. Gautier, S. Denis, Ch. Liebaut, S. Sjöström, A. Simon

\section{To cite this version:}

E. Gautier, S. Denis, Ch. Liebaut, S. Sjöström, A. Simon. Mechanical behaviour of Fe-C alloys during phase transformations. Journal de Physique IV Proceedings, 1994, 04 (C3), pp.C3-279-C3284. 10.1051/jp4:1994338. jpa-00252535

\section{HAL Id: jpa-00252535 https://hal.science/jpa-00252535}

Submitted on 1 Jan 1994

HAL is a multi-disciplinary open access archive for the deposit and dissemination of scientific research documents, whether they are published or not. The documents may come from teaching and research institutions in France or abroad, or from public or private research centers.
L'archive ouverte pluridisciplinaire HAL, est destinée au dépôt et à la diffusion de documents scientifiques de niveau recherche, publiés ou non, émanant des établissements d'enseignement et de recherche français ou étrangers, des laboratoires publics ou privés. 


\title{
Mechanical behaviour of Fe-C alloys during phase transformations
}

\author{
E. GAUTIER, S. DENIS, Ch. LIEBAUT, S. SJÖSTRÖMं* and A. SIMON \\ Laboratoire de Science et Génie des Matériaux Métalliques, Ecole des Mines, Parc de Saurupt, \\ 54042 Nancy cedex, France \\ ${ }^{*}$ Linköping Institute of Technology, 58183 Linköping, Sweden
}

\begin{abstract}
The mechanical behaviour of $\mathrm{Fe}-\mathrm{C}$ alloys have been determined in their phase transformation ranges during isothermal or anisothermal transformations. Two models an analytical model and a finite element model have been used in order to calculate the behaviour of the material. Considering a macroscopic scale, these models show that the mechanical behaviour can be well described when an additional deformation, i. e. the transformation plasticity deformation, is considered.
\end{abstract}

\section{INTRODUCTION}

The mechanical behaviour of two constituents materials has been studied experimentally by numerous authors and has been widely modelled when these constituents are considered as stable on a structural point of view (1-10). However only few results $(11,12)$ have been reported when the materials are deformed in their phase transformation range although such deformation conditions exist during thermomechanical treatments and even heat treatments when the material is submitted to internal stresses generated by the treatment itself. Also, on one hand, the mechanical behaviour of two $\mathrm{Fe}-\mathrm{C}$ alloys has been studied during the $\gamma \rightarrow \alpha+\mathrm{Fe} 3 \mathrm{C}$ phase transformations. An anisothermal transformation austenite $\rightarrow$ ferrite + perlite (the transformation occurs slowly during cooling), and an isothermal transformation, austenite $\rightarrow$ perlite have been considered. On another hand, the mechanical behaviour is modelled considering an "analytical model" using an hypothesis of homogeneous deformation between the two phases, and a finite element model (FEM) generally used in the calculation of internal stresses during quenching. The specific behaviour of the material during phase transformation is described at the macroscopic scale as an additional deformation. The different models are presented and calculations are compared to experiments.

\section{EXPERIMENTAL METHOD}

The two studied alloys are $\mathrm{Fe}-0.2 \mathrm{wt} \% \mathrm{C}$ and $\mathrm{Fe}-0.8 \mathrm{wt} \% \mathrm{C}$ with a content of $\mathrm{Mn}$ near $0.7 \mathrm{wt} \%$ and small additions of other elements (about $0.02 \% \mathrm{P}, 0.02 \% \mathrm{~S}, 0.15 \% \mathrm{Si}, 0.03 \% \mathrm{Al}, 0.04 \% \mathrm{Cu}, 0.024 \% \mathrm{Cr}$ in wt\%). Tests have been carried out with a thermomechanical simulator DITHEM designed and perfected in our laboratory. This apparatus is able to generate rapid thermal and mechanical variations while simultaneously recording sample deformation, applied load, temperature and electrical resistivity. For Fe$0.2 \mathrm{C}$ alloy, the specimen was austenitized at $1000^{\circ} \mathrm{C}$ during $15 \mathrm{~min}$ and cooled at a constant cooling rate $\left(0.5^{\circ} \mathrm{C} / \mathrm{s}\right)$ down up to $850^{\circ} \mathrm{C}$. During austenitization and the beginning of the cooling, a constant low stress ( $5 \mathrm{MPa}$ ) is applied to the sample. Also, the phase transformation can be studied by dilatometry. From $850^{\circ} \mathrm{C}$, the specimen is simultaneously cooled $\left(0.5^{\circ} \mathrm{C} / \mathrm{s}\right)$, and deformed at a constant deformation rate in the phase transformation range. The deformation rates have been chosen ranging from $10^{-5} \mathrm{~s}^{-1}$ to

$5.10^{-4} \mathrm{~s}^{-1}$. The simultaneous recording of the electrical resistivity variations allows to follow the structural modifications of the alloy. 
For the Fe- $0.8 \% \mathrm{C}$ alloy, after austenitization the sample is rapidly cooled down to its transformation temperature ( 665 or $675^{\circ} \mathrm{C}$ respectively) and the temperature is maintained constant while the specimen is deformed at a deformation rate of $5 \cdot 10^{-5} \mathrm{~s}^{-1}$.

\section{EXPERIMENTAL RESULTS}

The mechanical behaviour of the $\mathrm{Fe}-0.2 \% \mathrm{C}$ alloy measured during cooling is shown on figure 1 (for a similar cooling rate $0.5^{\circ} \mathrm{C} / \mathrm{s}$ ) on which stress variations versus temperature have been reported for the different applied deformation rates. During cooling, the flow stress of austenite increases as temperature decreases whatever the deformation rate. From $770^{\circ} \mathrm{C}$, the curves show two ranges where a softening of the material is measured. The recording of electrical resistivity variations allow us to correlate these softening domains to the austenite $\rightarrow$ ferrite transformation and the austenite $\rightarrow$ pearlite transformation $(13,14)$.

If we compare the behaviour corresponding to the two deformation rates, in the austenitic range for a same temperature, an increase of the flow stress is obtained when the deformation rate increases. At $770^{\circ} \mathrm{C}$, the deformation of the samples is quite different $0.16 \%$ for $\dot{\varepsilon}=10^{-5} \mathrm{~s}^{-1}$ and $8 \%$ for $5.10^{-4} \mathrm{~s}^{-1}$. The softening is also quite dependent on the deformation rate $29 \mathrm{MPa}$ for $\bar{\varepsilon}=10^{-5} \mathrm{~s}^{-1}, 22 \mathrm{MPa}$ for $\dot{\varepsilon}=5.10^{-5} \mathrm{~s}^{-1}$ and 13 MPa for $\dot{\varepsilon}=5.10^{-4} \mathrm{~s}^{-1}$ for the ferritic transformation range. In the pearlitic transformation range similar behaviours are observed.

The mechanical behaviour measured during the austenite $\rightarrow$ pearlite transformation is shown on figure 2 , where stress variations versus the deformation are plotted for two transformation temperatures 665 and $675^{\circ} \mathrm{C}$ and a deformation rate of $510^{-5} \mathrm{~s}^{-1}$. For $675^{\circ} \mathrm{C}$, a continuously increasing stress is obtained with the increase of deformation, however the apparent yield stress is lower than that of austenite at higher temperature. For $665^{\circ} \mathrm{C}$, a softening is observed at the low deformation values followed by an increase of the stress. Simultaneous electrical resistivity measurements allow to define the transformation range as shown on figure 2 . The softening obtained at $665^{\circ} \mathrm{C}$ is again observed in the phase transformation range.

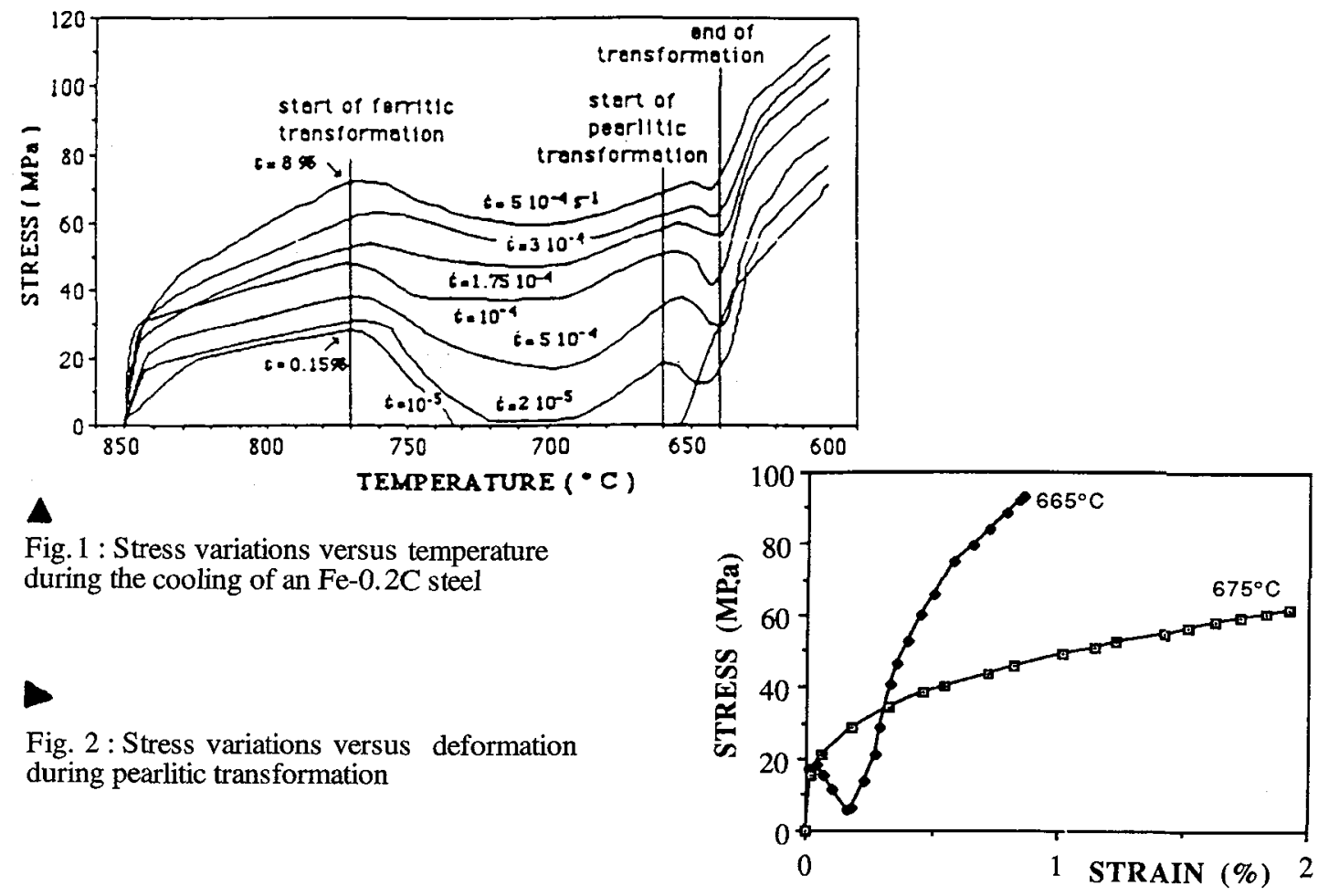




\section{MODELLING}

In order to model the mechanical behaviour a previous analysis was performed in order to define the origins of the observed softenings (13). Some obvious origins are : i) variations of the mechanical properties of the transformed phase compared to the parent phase. For example ferrite exhibits a lower flow stress $\left(\sigma_{\mathrm{y}}=28 \mathrm{MPa}\right.$ at $\left.790^{\circ} \mathrm{C}\right)$ than austenite at the same temperature $\left(\sigma_{\mathrm{y}}=36.5 \mathrm{MPa}\right)$, ii) the volumic variation due to the phase transformation which is positive and therefore can replace the required imposed deformation rate.

Indeed in the phase transformation range the different deformation sources are :

- thermal contraction which is negative $\varepsilon_{\mathrm{th}}=\alpha \Delta \mathrm{T} ; \alpha$ is the thermal expansion coefficient.

- volumic variation due to transformation $\varepsilon_{\mathrm{tr}}$ wich is positive and exists only in the phase transformation range.

- elastic and plastic deformations of the alloy. This is a "mechanical" deformation $\left(\varepsilon_{\mathrm{mec}}\right)$.

- transformation plasticity deformation : this additionnal deformation is observed when a material is deformed in its phase transformation range. Its origin is a function of the transformation progress and of the applied stress (15).

The mechanical deformation variations which govern the flow stress can be written as :

$$
\mathrm{d} \varepsilon_{\mathrm{mec}}=\mathrm{d} \varepsilon_{\mathrm{t}}-\mathrm{d} \varepsilon_{\mathrm{th}}-\mathrm{d} \varepsilon_{\mathrm{tr}}-\mathrm{d} \varepsilon_{\mathrm{tp}}
$$

where $\mathrm{d} \varepsilon_{\mathrm{t}}=\dot{\varepsilon} \mathrm{dt} ; \dot{\varepsilon}$ is the deformation rate applied to the sample.

In order to calculate the mechanical behaviour of the alloy deformed during cooling, the mechanical behaviour of austenite, ferrite and pearlite have been determined at constant temperatures for which only one constituent is present. For each constituent, the mechanical behaviour is mainly described by the following relation $\sigma=\mathrm{K} \varepsilon^{\mathrm{n}} \dot{\varepsilon}^{\mathrm{m}}[1]$.

The values of $\mathrm{K}, \mathrm{m}, \mathrm{n}$ are :

for ferrite :

$$
\mathrm{K}_{\alpha}(\mathrm{T})=-0.37 \mathrm{~T}+483
$$

$\mathrm{T}:\left[790-670^{\circ} \mathrm{C}\right]$

$$
\begin{aligned}
& \mathrm{m}_{\alpha}(\mathrm{T})=6.610^{-4} \mathrm{~T}-0.52 \\
& \mathrm{n}_{\alpha}(\mathrm{T})=-8.710^{-4} \mathrm{~T}+0.96
\end{aligned}
$$

for austenite

$\mathrm{T}:\left[850-725^{\circ} \mathrm{C}\right]$

$$
\mathrm{K}_{\gamma}(\% \mathrm{C}, \mathrm{T})=-1.05 \mathrm{~T}+214.3 \mathrm{C}+1393.6
$$

$\mathrm{m}_{\gamma}=0.14$

$$
\mathrm{n}_{\gamma}(\mathrm{T})=-2.310^{-4} \mathrm{~T}+0.4
$$

for pearlite

$\mathrm{T}:\left[660^{\circ} \mathrm{C}-620^{\circ} \mathrm{C}\right]$

$\mathrm{K}_{\mathrm{p}}(\mathrm{T})=-10.52 \mathrm{~T}+11147$

and $\varepsilon[0-2 \%]$

$\mathrm{m}_{\mathrm{p}}=0,20$

$\mathrm{n}_{\mathrm{p}}(\mathrm{T})=0.38-3,35 \cdot 10^{-4} \mathrm{~T}$

$\mathrm{T}$ is the temperature in Kelvin

$\mathrm{C}$ is the carbon content of austenite in $\mathrm{wt} \%$ which varies with temperature or transformation kinetics, $(\mathrm{C}=$ $(0.2-0.02 \mathrm{x}) /(1-\mathrm{x}), \mathrm{x}$ is the ferrite content), $\mathrm{m}$ is the sensitivity coefficient to strain rate, $\mathrm{n}$ is the strain hardening coefficient.

The mechanical properties of ferrite and pearlite are dependent on the temperature. For austenite they are also related to the change in the carbon composition. The grain size effect is not considered.

The mechanical behaviour during cooling is calculated using two models. For the "analytical model", we assume that the strain increments in the two constituents are the same (homogeneous strain hypothesis). For the "analytical model", the flow stress of the multi-constituent material is written as a mixing rule between the flow stress of each phase $\sigma_{i}, \sigma_{i}$ being calculated with the above equations and $x_{i}$ the volume fraction of constituent $i$ :

The thermal deformation increment is defined as :

$$
\sigma=\sum \sigma_{\mathrm{i}} \mathrm{x}_{\mathrm{i}}
$$

$$
\mathrm{d} \varepsilon_{\mathrm{th}}=\dot{\mathrm{T}} \mathrm{dt} \sum \alpha_{\mathrm{i}} \mathrm{x}_{\mathrm{i}}
$$

where $\alpha_{i}$ is the expansion coefficient of constituent $i$ (assumed constant). 
The deformation associated to the volume variation during the transformation increase $d x_{i}$, is $d \varepsilon_{t r}=\varepsilon_{t r} d x_{i}$ $\varepsilon_{\mathrm{tr}}$ is the deformation associated to the transformation and measured by dilatometry.

At last, the transformation plasticity deformation is considered as linearly related to the applied stress $\sigma$ and to the progress of the transformation $\mathrm{dx}_{\mathrm{i}}(15)$.

$$
\mathrm{d} \varepsilon_{\mathrm{tp}}=\mathrm{K}^{\prime} \sigma \mathrm{dx} \mathrm{x}_{\mathrm{i}}
$$

The considered value of $\mathrm{K}^{\prime}$ is the one obtained by de Jong and Rathenau (16), for an Fe-C steel with a similar composition : $\mathrm{K}^{\prime}=3.10^{-4} \mathrm{MPa}^{-1}$. Only one value of $\mathrm{K}^{\prime}$ is considered.

We also used a finite element model at a macroscopic scale. This model is generally used for the calculation of internal stresses during heat treatments considering possible phase transformations $(17,18)$. Also it needs an accurate description of the mechanical behaviour of the material. In this model the constitutive law is considered as thermoelastoplastic. The mechanical properties of the multi-constituent material again are obtained from the single constituent materials using a mixture rule. The mechanical input data are the yield stress, the Young's modulus and the strain hardening constant for each phase. The Young' s modulus values have been obtained from the literature (19) and are dependent on the temperature. The strain hardening coefficients were also temperature dependent and obtained from experiment. The yield stress corresponds to the flow stress calculated with the relation [1] for a deformation of 0.005 , and the yield stresses of pearlite are in that case corrected for the grain size effect, taking into account a correction factor of 1.5 (14). Isotropic hardening was considered.

For the finite element model, the triaxial evolution of transformation plasticity deformation is :

$$
d \varepsilon_{i j}^{t p}=\frac{3}{2} K^{\prime} d x_{i} S_{i j}
$$

For the two models, the material looses its "memory" of plastic strain accumulated in austenite during transformation.

The transformation kinetics is given as an input data, and is the one obtained from dilatometry measurements (14). For the chosen cooling rate the effects of stress/strain on transformation kinetics are considered as being negligible.

On figure 3 the variations of stress versus strain are given for the $\mathrm{Fe}-0.2 \mathrm{C}$ alloy calculated by the analytical model, considering the deformation rate of $2.10^{-5} \mathrm{~s}^{-1}$. Different calculations were made considering i) the change in mechanical properties and the volumic variation associated to the transformation and ii) the change in mechanical properties, the volumic variation and the transformation plasticity deformation. In the austenitic range, the mechanical behaviour is nearly well described during the cooling. The calculated flow stress is lower than the experimental one, and the difference increases, as the deformation increases and the temperature decreases. When transformation occurs, we observe that the first calculation describes only a small softening in the ferritic transformation range, and in the pearlitic transformation range, we don' $t$ calculate any softening. For the second case, the calculated softening in the ferritic transformation range is very near the one measured. However, for the end of the ferritic transformation some discrepancies appear. In the pearlitic range, a softening is calculated for that case, the magnitude of the softening is similar to the experimental one, but the increase in mechanical properties is obtained at a lower deformation value.

The results obtained with the finite element model, are shown on figure 4 and compared to the experiment. The mechanical behaviour of the austenite is again well described. Some differences appear, namely at the beginning of the test that can be attributed to the constitutive law considered in the model (compared to the previous calculation). When the austenite transforms, a softening is calculated, which occurs later than the experimental one as for the previous calculation. At the end of the ferritic transformation, a rapid increase of the stress is calculated, leading to large differences between the model and the experience. At least in the pearlitic transformation range, a rapid decrease of the stress is calculated, leading to negative values of the axial stress (near zero). The rapid increase of stress for pearlite is well described. Compared to the previous calculation, a larger difference between calculated and experimental values is obtained for the finite element model at the end of the ferritic transformation. It can mainly be attributed to the elastoplastic law considered in that model and the way the input data are considered (Young's modulus values have been taken from the literature and the yield stress values are determined for an $\varepsilon$ value of $0.5 \%$, leading to a stiffer behaviour than the measured one). A viscoelastoplastic behaviour or a description considering the yield stress for a lower value of $\varepsilon$ should be introduced in order to reach a better description of the material in the very first deformation ranges. Moreover, these large stress values obtained at the end of the ferritic transformation will lead to a large transformation plasticity contribution and explain the large stress drop to a zero stress value in the pearlitic transformation range. 


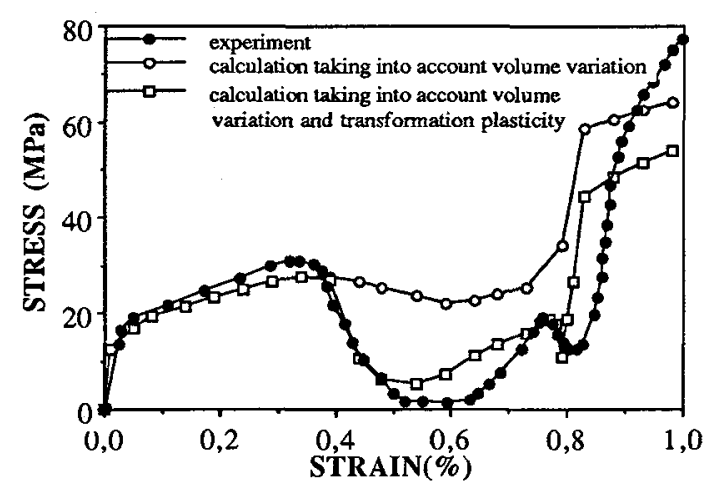

Fig. 3 : Calculated and measured stress variations versus deformation $\dot{\varepsilon}=210^{-5} \mathrm{~s}^{-1}$ (analytical model)

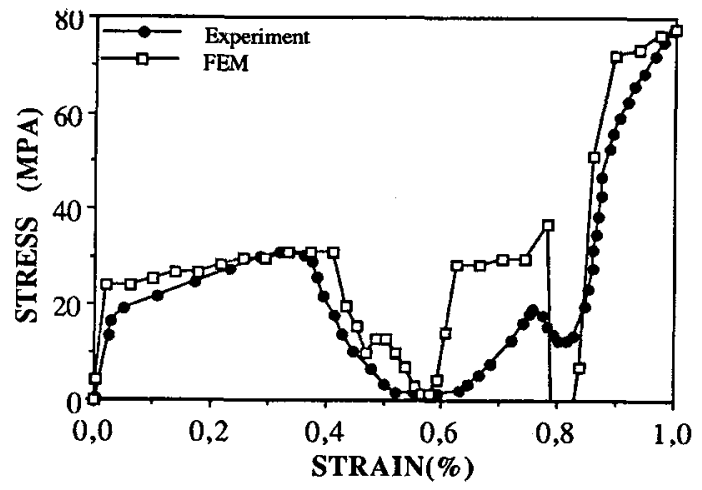

Fig 4. : Calculated and measured stress variations versus deformation. (FEM model)

The results calculated with the analytical model for the isothermal pearlitic transformation are given on figure 5. The transformation kinetics is estimated from resistivity measurements, which lead to the estimation of the beginning and the end of the transformation kinetics. A Johnson-Mehl-Avrami kinetics is then considered from these determinations. The mechanical behaviour of austenite is similar to the one used in the previous calculations, and that of pearlite is considered as elastic perfectly plastic. The yield stress of pearlite is considered as being equal to $85 \mathrm{MPa}$. For the transformation temperature of $675^{\circ} \mathrm{C}$, the experimental curve is very well described up to a deformation of $0.6 \%$, i.e. a transformation content of 50 $\%$. For larger transformation contents, the calculated stress is always larger than the measured one. For $665^{\circ} \mathrm{C}$, the general shape of the mechanical behaviour is obtained, but some differences are still remaining.

The analysis of the calculated results (i.e. $d \varepsilon_{m e c}$ and $d \varepsilon_{t p}$ ) showed that the mechanical behaviour is such as the applied stress tends to a value which will give a transformation plasticity deformation and a volumic variation rate equal to the applied deformation rate (i.e. $\mathrm{d} \varepsilon_{\text {mec }}$ tends to 0 ). We are then able to explain the decrease in the apparent yield stress of the material when the temperature decreases from 675 to $665^{\circ} \mathrm{C}$. For the last temperature, the transformation kinetics is more rapid than for $675^{\circ} \mathrm{C}$. Also to reach the applied deformation rate, the transformation plasticity and volumic variation contribution equal to $\left(1 / 3 \varepsilon_{\mathrm{tr}}+\mathrm{K} \sigma\right) \mathrm{dx}_{\mathrm{i}}$ due to its increase in $\mathrm{dx}_{\mathrm{i}}$ will require a lower stress than for $675^{\circ} \mathrm{C}$.
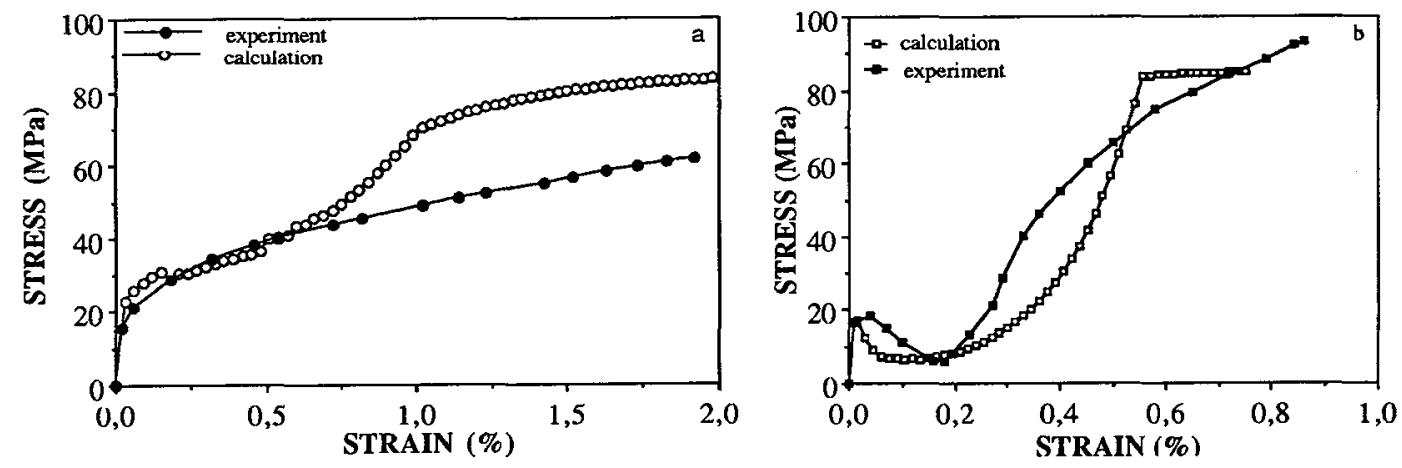

Fig. 5 : Calculated and measured stress variations versus deformation during isothermal pearlitic transformations $\left(\dot{\varepsilon}=510^{-5} \mathrm{~s}^{-1}\right)$.a) $675^{\circ} \mathrm{C}$ b) $665^{\circ} \mathrm{C}$ 
The mechanical behaviour will then largely depend on the deformation rate and the ratio deformation rate/transformation rate. For a same deformation rate, an increase in the transformation rate will lead to larger softenings and to a decrease in the apparent yield stress. For a same transformation rate, larger deformation rates will limit the softenings, even they are no more observed and a plastic deformation of the phases occurs.

These different simulations of the mechanical behaviour during phase transformation show that considering a macroscopical modelling, the transformation plasticity deformation has to be considered and can be written as an additional strain in the phase transformation range. Its essential contribution occurs when the transformation plasticity deformation and the volumic variation correspond to the total deformation imposed to the material ; the flow stress is difficult to predict and may be much lower than the flow stress of the softest phase. If a plastic deformation is needed, the difference in the flow stress calculated with or without considering transformation plasticity deformation will essentially be dependent on the material hardening $(14,20)$.

\section{CONCLUSION}

The mechanical behaviour in the phase transformation range has been studied and modelled. A macroscopical approach considering the transformation plasticity as an additional deformation allows to describe the mechanical behaviour for the studied transformations (ferritic and pearlitic) in isothermal or anisothermal conditions.

The results show that it is necessary to take into account the transformation plasticity deformation namely for the low deformation rates and the large transformation progress rates.

\section{REFERENCES}

11/ G.B. OLSON, Encyclopedia of Materials Science and Engineering, Ed. M.B. BEVER, Pergamon Press (1982).

12/ F. ABRASSART, Thèse de Doctorat ès Sciences Physiques, Université de Nancyl France, (1972)

B/ A. NAJAFI-ZADEH, M. HARMELIN, G. CHAPPUIS, P. LEHR, Rapport de Recherches 160, Ecole Nationale Supérieures des Techniques Avancées, Mars 1982.

14/ Y. SAITO, Trans. Iron Steel Inst. Jpn, 27 (1987) 419.

$15 /$ B.O. SUNDSTRÖM, Mater. Sci. Engng, 12 (1973) 265.

/6/ J. JINOCH, S. ANKEN, H. MARGOLIN, Mater. Sci. Engng, 34 (1978) 203.

nI M. BERVEILLER, A. HIHI, A. ZAOUI, Proc. 2nd RISO Int. Symp. on Metallurgy and Materials Science (1981) 145.

18/ M. BERVEILLER, A. ZAOUI, Proc. 4th RISO Int. Symp. on Metallurgy and Materials Science ( 1983) 153.

19/ Y. YOMOTA, I. TAMURA, Trans. Iron Steel Inst. Jpn, 22 (1982) 665.

/10/ C. THOMAS de MONTPREVILLE, Res. Mec. 7 (1983) 211.

/11/ T. NARUTANI, G.B. OLSON and M. COHEN, Proc. ICOMAT, Journal de Physique, Colloque C4, sup. 12, 43 (1982), C4-429.

/12/ E. PATOOR, A. EBERHARDT, M. BERVEILLER, Acta Metall. 35 (1987) 2779.

113/ LIEBAUT Ch., GAUTIER E. and SIMON A., Proc THERMEC 88, I.S.I.J Ed. I. Tamura, (1988) 146.

/14/ LIEBAUT Ch.,Thèse de Doctorat de l'INPL, Nancy (1988).

/15/ GAUTIER E., SIMON A.and BECK G.,Acta Metall 35 (1987) 1367.

/16/ DE JONG M.and RATHENAU G.W., Acta Metall 9, (1961)714

/17/ SJÖSTRÖM S., Mat. Sci. and Tech. 1, (1985) 823.

/18/ DENIS S., SJÖSTRÖM S. and SIMON A., Metall. Trans A, 18A, (1987)1203.

/19/ VIDAL G., LESCOP P., and RAYMONDIN L., Rev. Métal. XLVIII, (1951) 864.

/20/ DENIS S., SIMON A., Proc. ICRS1, D.G.M. Ed. E. Macherauch, V. Hauk, 2, (1986)565. 